\title{
Point Defect Incorporation During Diamond Chemical Vapor Deposition
}

\author{
C.C. Battaile*, D.J. Srolovitz ${ }^{\dagger}$, J.E. Butler ${ }^{\ddagger}$ \\ *Materials and Process Computation and Modelinǵ, Org 1834 \\ Sandia National Laboratories \\ Albuquerque, NM 87111-1411 USA \\ ${ }^{\dagger}$ Materials Science and Engineering \\ University of Michigan \\ Ann Arbor, MI 48109-2136 USA \\ ${ }^{\ddagger}$ Gas/Surface Dynamics Section, Code 6174 \\ Naval Research Laboratory \\ Washington DC 20375-5342 USA
}

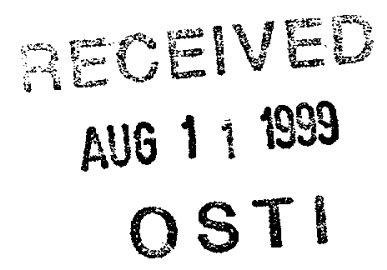

\section{Abstract}

The incorporation of vacancies, $\mathrm{H}$ atoms, and $\mathrm{sp}^{2}$ bond defects into single-crystal homoepitaxial (100)(2x1)- and (111)-oriented CVD diamond was simulated by atomic-scale kinetic Monte Carlo. Simulations were performed for substrate temperatures from $600^{\circ} \mathrm{C}$ to $1200^{\circ} \mathrm{C}$ with $0.4 \% \mathrm{CH}_{4}$ in the feed gas, and for $0.4 \%$ to $7 \% \mathrm{CH}_{4}$ feeds with a substrate temperature of $800{ }^{\circ} \mathrm{C}$. The concentrations of incorporated $\mathrm{H}$ atoms increase with increasing substrate temperature and feed gas composition, and $\mathrm{sp}^{2}$ bond trapping increases with increasing feed gas composition. Vacancy concentrations are low under all conditions. The ratio of growth rate to $\mathrm{H}$ atom concentration is highest around $800-900{ }^{\circ} \mathrm{C}$, and the growth rate to $\mathrm{sp}^{2}$ ratio is maximum around $1 \% \mathrm{CH}_{4}$, suggesting that these conditions are ideal for economical diamond growth under the simulated conditions. 


\section{Introduction}

Many of diamond's technologically promising mechanical, optical, and electronic properties can be dramatically affected by the presence of defects in the solid material. When diamond is chemically deposited from a vapor to produce thin films, these defects are incorporated primarily during the growth process [1]. Extended defects like grain boundaries, twins, and dislocations are common in CVD diamond [1-3], as are point defects like vacancies, impurities (e.g., $\mathrm{H}, \mathrm{N}, \mathrm{B}$ ), and $\mathrm{sp}^{2}$ (non-diamond) $\mathrm{C}-\mathrm{C}$ bonds $[1,3]$. While twins and dislocations are known $[1,4,5]$ to form in the diamond lattice as it grows, the details of these processes are not well understood. Point defects can be trapped in the film when material overgrows surface adsorbates or vacant lattice sites. Under typical low-pressure CVD conditions, growth of the thermodynamically stable graphitic $\mathrm{C}$ phase is suppressed by the $\mathrm{H}$-promoted growth of $\mathrm{sp}^{3}$ bonded $\mathrm{C}$, though the formation of at least some $\mathrm{sp}^{2}$-bonded material is common.

Defects in diamond films can be detected ex situ by a variety of techniques [1]. Direct observation of the processes that lead to defect production and incorporation, however, is not currently possible. Diamond is generally deposited at elevated temperatures $\left(700\right.$ to $\left.1200^{\circ} \mathrm{C}\right)$ in a hydrogen plasma at 10-100 Torr pressure, and detailed in situ probing of the growth surface or the bulk material in this environment is difficult. Defect incorporation mechanisms that involve chemical processes, such as the formation and etching of $\mathrm{sp}^{2} \mathrm{C}$ bonds, can be studied using simple kinetic models of diamond growth [6,7]. However, point and extended defect formation processes are inherently atomistic in nature, and a representation of diamond growth in three dimensions and on the atomic level is helpful if a realistic and meaningful treatment of defect formation is to be attempted.

Three-dimensional atomic-scale models of diamond growth have recently been used to investigate growth behavior and film morphology. Dawnkaski et al. [8] simulated the growth rate and morphology on the $(100)(2 \times 1)$ surface by computing transitions between surface states using a 


\section{DISCLAIMER}

This report was prepared as an account of work sponsored by an agency of the United States Government. Neither the United States Government nor any agency thereof, nor any of their employees, make any warranty, express or implied, or assumes any legal liability or responsibility for the accuracy, completeness, or usefulness of any information, apparatus, product, or process disclosed, or represents that its use would not infringe privately owned rights. Reference herein to any specific commercial product, process, or service by trade name, trademark, manufacturer, or otherwise does not necessarily constitute or imply its endorsement, recommendation, or favoring by the United States Government or any agency thereof. The views and opinions of authors expressed herein do not necessarily state or reflect those of the United States Government or any agency thereof. 


\section{DISCLAIMER}

Portions of this document may be illegible in electronic image products. Images are produced from the best available original document. 
kinetic Monte Carlo approach. Clark et al. [9] used a hybrid on- / off-lattice Monte Carlo technique to simulate the early stages of growth on a (111) diamond substrate. Though these models are simplified to allow the consideration of realistic deposition times, they contain physically meaningful representations of the atomic processes that lead to diamond growth. However, the atomic-scale generation and incorporation of defects during diamond CVD have only been discussed in brief [10]. In this paper we report predictions of vacancy, $\mathrm{H}$ atom, and $\mathrm{sp}^{2} \mathrm{C}-\mathrm{C}$ bond densities in CVD diamond based on our modeling studies. Homoepitaxial growth on diamond substrates in (100) and (111) orientations is simulated atom-by-atom using a kinetic Monte Carlo procedure. The rates of the surface processes that lead to growth are obtained from conventional surface chemical reaction mechanisms and thermochemistry $[6,11-13]$. The densities of vacancies, $\mathrm{H}$ atoms, and $\mathrm{sp}^{2}$ defects are computed using the hot-filament CVD reactor conditions considered previously by Coltrin and Dandy [6], and the implications of these predictions for optimizing hot-filament growth conditions are addressed. The detailed reaction dynamics of growth on the (100) surface of diamond are not well understood $[8,12]$ and are currently under investigation by several groups. Hence, the modeling presented here will employ our current level of understanding of the mechanisms, and may require refinement when the (100) reaction dynamics are better understood.

\section{Method}

Diamond is typically deposited in a hydrogen atmosphere [3]. A feed gas of $\mathrm{H}_{2}$ containing a small fraction (about $1 \%$ ) of a hydrocarbon precursor (often $\mathrm{CH}_{4}$ ) is activated by exposure to a heat source (e.g., hot filament, microwave plasma, or dc arcjet). This dissociates some of the $\mathrm{H}_{2}$ into atomic $\mathrm{H}$ and evolves various hydrocarbon species (most importantly $\mathrm{CH}_{3}$ and $\mathrm{C}_{2} \mathrm{H}_{2}$ ). The atomic $\mathrm{H}$ passivates the radical $\mathrm{C}$ bonds at the diamond surface and preferentially etches $\mathrm{sp}^{2}-$ bonded $\mathrm{C}$ material. Atomic $\mathrm{H}$ in the gas activates surface sites by recombining with adsorbed $\mathrm{H}$ atoms in an abstraction reaction (see below). Solid material is deposited when hydrocarbons from 
the gas chemisorb onto the activated sites and react with one another and the surface to add $\mathrm{sp}^{3}$ - or $\mathrm{sp}^{2}$-bonded $\mathrm{C}$ to the film. In this work, we simulate diamond deposition in a hot-filament growth environment (see below), since this is the most characterized environment reported in the literature [14-16].

The chemistry underlying diamond deposition involves primarily $\mathrm{C}$ and $\mathrm{H}$, and a vast database of information about the chemical interactions between $\mathrm{C}$ - and $\mathrm{H}$-containing species is available from studies of combustion [17]. This information can be combined with spectral analysis and $a b$ initio calculations to estimate the kinetics of many of the processes that are important to diamond CVD. The kinetics for the reverse reactions can be estimated from the forward rates and the equilibrium reaction thermochemistry. This approach has been used to construct several diamond CVD reaction mechanisms, and the set of chemical reactions listed in Table I was compiled from several sources $[6,11-13]$. In Table I, $C_{d}$ represents a surface diamond atom, $\mathrm{C}_{\mathrm{g}}$ is a "graphitic $\mathrm{C}$ atom" (i.e., an $\mathrm{sp}^{2}$-bonded $\mathrm{C}$ atom, following the notation of Coltrin and Dandy [6]), species separated by a bullet $(\bullet)$ are dimer bonded, and an asterisk $\left(^{*}\right)$ represents a surface biradical. Forward rate constants are $k_{f}=A T^{n} \exp (-E / R T)$ and reverse rate constants are $k_{r}=C A T^{n} \exp (-S / R) \exp ((H-E) / R T)$, where $C$ is a constant that accounts for the fact that $H$ and $S$ correspond to a standard state of $1200 \mathrm{~K}$ and 1 atm [12]. $C$ is equal to $1.016 \times 10^{-5} \mathrm{~mole} \bullet \mathrm{cm}$ $3 /$ atm for reactions where the number of moles changes (i.e., the number of products and reactants are unequal) and unity otherwise.

Reactions 1 and 2 are between $\mathrm{H}$ and the diamond surface. Reactions 3-5 occur between hydrocarbon molecules and the surface. Reactions 6-9 are between $\mathrm{H}$ and chemisorbed hydrocarbons. Reactions 10 and 11 represent the addition of $\mathrm{CH}_{3}$ to an adsorbed hydrocarbon. Reactions 13-16 handle hydrogen and hydrocarbon molecules interacting with dimer-bonded surface atoms, and Reactions 18-22 account for hydrogen and hydrocarbon reactions with $\mathrm{sp}^{2}-$ bonded surface sites. (Reactions 5-11 apply to any surface site.) Reaction 17 represents formation / breaking of dimer bonds between surface atoms [18], Reaction 12 represents insertion of a hydrocarbon into an opened dimer bond [18], and Reaction 23 is the interconversion between $\mathrm{sp}^{2}$ - 
and $\mathrm{sp}^{3}$-bonded $\mathrm{C}$ atoms at the surface [6]. The reactions involving $\mathrm{H}$ and $\mathrm{CH}_{3}$ attachment to $\mathrm{sp}^{3}-$ and dimer-bonded surface atoms (Reactions 1-11 and 13-16), and those describing dimer bonding (Reactions 12 and 17), were adopted from the work of Harris and Goodwin [12]. The $\mathrm{C}_{2} \mathrm{H}_{2}$ kinetics (Reaction 5) were taken from the $a b$ initio calculations of Skokov et al. [13]. All reactions involving $\mathrm{sp}^{2}$-bonded $\mathrm{C}$ (Reactions 18-23) were taken from the modeling of Coltrin and Dandy [6]. According to their estimates, all reactions at $\mathrm{sp}^{2}$-bonded surface $\mathrm{C}$ atoms proceed at $1 / 10$ th the rate of the corresponding reaction at an $\mathrm{sp}^{3}$-bonded site, with the exception of $\mathrm{H}$ abstraction which occurs at $1 / 100$ th the rate. Thus, the forward reaction rates for Reactions $19-22$ were obtained simply by scaling the rates of Reactions $2-4$ by $1 / 10$, and the rate of Reaction 18 is $1 / 100$ th the rate of Reaction 1. The thermochemistry for Reactions 18-21 are from Ref. [6], and that for Reaction 22 is the same as Reaction 5. The rate and thermochemistry for Reaction 23 is same as in Ref. [6]. Scaling the reaction rates in the manner described above insures that the reactions involving sites on $\mathrm{sp}^{2}$-bonded $\mathrm{C}$ atoms are compatible with the reaction set of Harris and Goodwin [12]. The reaction mechanism from Harris and Goodwin [12] is used here since Coltrin and Dandy [6] consider diamond growth in a dc arcjet reactor, and their reaction mechanism is not entirely appropriate for the hot filament CVD growth simulated here. The reaction rate data for $\mathrm{sp}^{2}$-related reactions were adopted from Coltrin and Dandy [6] because Harris and Goodwin [12] do not consider $\mathrm{sp}^{2}$ bond formation in their analysis.

The rate coefficients in Table I can be used to calculate the reaction rate constants in units of either moles $\mathrm{cm}^{-3} \mathrm{sec}^{-1}$ for reactions involving a reactant in the gas, or $\mathrm{sec}^{-1}$ otherwise. In the former case, the absolute reaction rate in units of $\sec ^{-1}$ can be obtained by adjusting the rate constant by the ideal partial molar volume $\left(\chi_{i} P / R T\right)$ of the gas-phase reactant. Thus a kinetic analysis of diamond growth using chemical reactions like those in Table I requires some knowledge or estimate of several environmental variables: the substrate temperature $(T)$, the pressure $(P)$, and the concentrations of the gas-phase species at the growth surface $\left(\chi_{i}\right)$. Dandy and Coltrin [19] have reported predictions of the $\mathrm{H}, \mathrm{CH}_{3}$, and $\mathrm{C}_{2} \mathrm{H}_{2}$ concentrations at the growth surface in a hot-filament reactor, and their estimates agree well with the experimental measurements 
of Hsu [15]. The modeled growth conditions correspond to a feed gas containing $\mathrm{H}_{2}, 7 \% \mathrm{Ar}$, and various concentrations of $\mathrm{CH}_{4}$, injected into a 20.25 Torr growth chamber at $1 \mathrm{~cm} / \mathrm{s}$ over a $2347^{\circ} \mathrm{C}$ filament located $1.3 \mathrm{~cm}$ from a $800^{\circ} \mathrm{C}$ diamond substrate. In order to convert the reaction rate constants in Table I into absolute reaction rates suitable for input to a Monte Carlo algorithm, we have adopted the hot-filament reactor gas-phase concentration data from the modeling of Dandy and Coltrin [19].

The diamond growth simulations start on a $\mathrm{H}$-passivated diamond substrate. All lattice sites are fixed at their diamond cubic positions. The temporal evolution of the diamond surface is simulated using a kinetic Monte Carlo procedure [20]. Any surface site that is occupied by the reactant or product of one or more reactions in Table I can evolve according to the pertinent reaction(s). Events occur stochastically on the surface according to their reaction rates. At each simulation step, one reaction is randomly chosen to occur at one surface site with a probability equal to the rate of the reaction relative to the sum of the rates of all the events (i.e., all possible reactions at all sites) that can occur at that simulation step. Thus fast processes are more likely to be chosen than slow ones. Since one event occurs at each simulation step, the time increment is not constant and is proportional to the inverse of the sum of the rates of all the events that are possible at the particular simulation step [21].

As the surface evolves according to this Monte Carlo procedure, it will be covered by various combinations of radical ("empty") sites, $\mathrm{H}$ atoms, and hydrocarbon chemisorbates, all of which will evolve according to the site-by-site reactions in Table I. Diamond and $\mathrm{sp}^{2}$-bonded C growth occurs by the conversion of chemisorbed hydrocarbons into solid C. A cluster of one or more hydrocarbons is incorporated into the film whenever it is bonded to the surface at two or more sites. (Hydrocarbon clusters can form when one or more $\mathrm{CH}_{3}$ or $\mathrm{C}_{2} \mathrm{H}_{2}$ molecules deposit next to one another on the surface.) Since growth is simulated on a rigid lattice, the geometries of large non-diamond $\mathrm{C}$ complexes cannot be represented. To allow $\mathrm{sp}^{2}$ bond formation in spite of this limitation, all $\mathrm{C}$ atoms in the film are labelled as either $\mathrm{sp}^{3}-$ or $\mathrm{sp}^{2}$-bonded $\mathrm{C}$. As each $\mathrm{C}$ atom in a hydrocarbon cluster is converted to "solid" material on the surface, the probability that it will 
be labelled as "sp"-bonded" is equal to the fraction of its $\mathrm{C}$ neighbors that are themselves $\mathrm{sp}^{2}$ bonded. The starting substrate contains only $\mathrm{sp}^{3}$-bonded $\mathrm{C}$, and conversion of surface $\mathrm{C}$ pairs to $\mathrm{sp}^{2}$-bonded $\mathrm{C}$ and back again via $\mathrm{H}$-assisted "etching" occurs according to Reaction 23 . The kinetics and necessary surface configuration for this reaction are those proposed by Coltrin and Dandy [6], i.e., a pair of $\mathrm{sp}^{3}$-bonded $\mathrm{C}$ atoms on the surface can convert to $\mathrm{sp}^{2}$-bonded $\mathrm{C}$ if the first has one $\mathrm{H}$ neighbor and three $\mathrm{C}$ neighbors, and the second has one radical site, one $\mathrm{H}$ neighbor, and two $\mathrm{C}$ neighbors. Any $\mathrm{sp}^{2}$-bonded $\mathrm{C}$ atom pair on the surface can be converted back to $\mathrm{sp}^{3}$-bonded $\mathrm{C}$ by the reverse of Reaction 23 .

Vacant (i.e., radical) sites, $\mathrm{H}$ atoms, and $\mathrm{sp}^{2}$-bonded $\mathrm{C}$ atoms are trapped into the film whenever they become completely overgrown by diamond (i.e., all neighbor sites are $\mathrm{sp}^{3}$-bonded C). Once this has occurred, the defect site no longer participates in chemical reactions. Although this treatment of $\mathrm{sp}^{2}$ bond formation and defect trapping is clearly a simplified treatment, it does capture the kinetics appropriate to $\mathrm{sp}^{2}$ bond formation and the atomic processes by which defects are trapped into the film as it grows.

The simulation method discussed above provides a simplified picture of diamond growth. It neglects thermal vibrations, atomic relaxations, surface diffusion, twin formation, and other effects that might be important to the growth process under some conditions. The treatment of $\mathrm{sp}^{2}$ bond formation, after Coltrin and Dandy [6], is drastically simplified, and is designed primarily to capture only the kinetics of $\mathrm{sp}^{2}-\mathrm{sp}^{3}$ interconversion on the diamond surface. Nonetheless, the simulation method as a whole captures the effects of both surface chemical kinetics and surface atomic configuration. Furthermore, it includes a simple yet realistic representation of defect trapping by overgrowth. The discussion above contains a cursory description of the diamond growth model and the kinetic Monte Carlo algorithm, and the reader is referred to Ref. [20] for a more complete treatment.

The incorporation of vacancies, $\mathrm{H}$ atoms, and $\mathrm{sp}^{2} \mathrm{C}$ was simulated for several substrate temperatures and feed gas compositions. The (100)- and (111)-oriented diamond substrates contain 288 and 300 surface atoms, respectively, and periodic boundary conditions are imposed parallel to 
the surface plane to simulate effectively larger substrates. The surfaces of the (100) substrates start in the $(100)(2 \times 1)$ dimer row reconstruction. The near-surface growth environment was adopted from the modeling of Dandy and Coltrin [19], as discussed above. The hot filament reactor conditions considered here correspond to a feed gas of $\mathrm{H}_{2}$ with $7 \% \mathrm{Ar}$ and varying concentrations of $\mathrm{CH}_{4}$, injected into a 20.25 Torr growth chamber at $1 \mathrm{~cm} / \mathrm{s}$ over a $2347^{\circ} \mathrm{C}$ filament located 1.3 $\mathrm{cm}$ from a $800^{\circ} \mathrm{C}$ diamond substrate. The concentrations of the gas-phase species as functions of the $\mathrm{CH}_{4}$ concentration in the feed are given in Fig. 1 [19]. Simulations were performed for substrate temperatures from 600 to $1200^{\circ} \mathrm{C}$ with a constant gas composition at the growth surface corresponding to $0.4 \%$ inlet $\mathrm{CH}_{4}$ in Fig. 1. (The gas composition was assumed independent of substrate temperature in lieu of the relevant data.) Simulations were also performed for inlet $\mathrm{CH}_{4}$ concentrations from 0.4 to $7.0 \%$ at a constant substrate temperature of $800{ }^{\circ} \mathrm{C}$ using the data in Fig. 1 to specify the composition of the gas at the growth surface. Sixty atomic layers (about 18,000 atoms) were deposited in each simulation, and five simulations were performed for each growth environment to obtain acceptably precise statistics. For each set of growth conditions (substrate temperatures and feed gas compositions), the growth rates and defect densities were calculated.

\section{Growth Rates}

The growth rates of (100)- and (111)-oriented films as functions of substrate temperature (at $0.4 \%$ inlet $\mathrm{CH}_{4}$ ) and as functions of inlet $\mathrm{CH}_{4}$ concentration (at $800{ }^{\circ} \mathrm{C}$ substrate temperature) are shown in Fig. 2. As the substrate temperature increases in Fig. 2a, the growth rates increase because the rate of $\mathrm{H}$ abstraction (Reaction 1 ), which is the dominant mechanism for activating growth sites, increases. However, the desorption of $\mathrm{CH}_{3}$ and $\mathrm{C}_{2} \mathrm{H}_{2}$ from the surface (the reverse of Reactions 4 and 5, respectively) becomes rapid at elevated temperatures, and the growth rates decrease with increasing temperature at high temperatures. These growth kinetics are similar to those reported by us in an earlier paper [10].

C.C. Battaile, D.J. Srolovitz, J.E. Butler "Simulations of Defect Incorporation During Diamond CVD" 
The growth rates increase as the concentration of $\mathrm{CH}_{4}$ in the feed gas increases, as shown in Fig. 2b. Changing the $\mathrm{CH}_{4}$ content in the feed gas alters the growth rate primarily by influencing the concentrations of $\mathrm{CH}_{3}$ and $\mathrm{C}_{2} \mathrm{H}_{2}$ at the growth surface. Since growth can occur only after $\mathrm{CH}_{3}$ or $\mathrm{C}_{2} \mathrm{H}_{2}$ deposition, the growth rate is directly related to the concentrations of these hydrocarbons in the gas at the surface. As more $\mathrm{CH}_{4}$ is supplied to the growth chamber, the concentration of growth species $\left(\mathrm{CH}_{3}\right.$ and $\left.\mathrm{C}_{2} \mathrm{H}_{2}\right)$ at the growth surface increases, yielding an increase in the growth rates.

\section{Vacancies and Trapped Hydrogen}

The concentrations of vacancies and $\mathrm{H}$ atoms are shown as functions of temperature in Fig. 3a and as functions of inlet $\mathrm{CH}_{4}$ in Fig. 3b. As the substrate temperature is increased in Fig. 3a, the concentration of incorporated $\mathrm{H}$ atoms increases from less than $0.01 \%$ to near $3 \%$ in the (100) films and above $1 \%$ in the (111) films. The vacancy concentrations in Fig. $3 \mathrm{a}$ are below $0.1 \%$ at most temperatures, and are below $0.01 \%$ at most of the $\mathrm{CH}_{4}$ concentrations in Fig. $3 \mathrm{~b}$. The $\mathrm{H}$ atom concentrations in the (100) films increase from about $0.03 \% \mathrm{H}$ at $0.4 \%$ inlet $\mathrm{CH}_{4}$ to $0.4 \% \mathrm{H}$ at $7 \% \mathrm{CH}_{4}$, and in the (111) films from $0.2 \% \mathrm{H}$ at $0.4 \% \mathrm{CH}_{4}$ to $0.8 \% \mathrm{H}$ at $7 \% \mathrm{CH}_{4}$. The concentrations of vacancies are much lower than those of $\mathrm{H}$ atoms because a vacant site is more likely to be filled than covered by diamond material, whereas an $\mathrm{H}$ atom site can be covered by diamond but not filled.

High vacancy concentrations are uncommon in CVD diamond [1], and the results in Fig. 3 are consistent with this observation. A comprehensive and systematic experimental study of the dependence of incorporated $\mathrm{H}$ atom density on processing conditions is not available, but $\mathrm{H}$ atom concentrations around $0.5 \%$ are commonly measured [22-24] in CVD diamond, and up to $1.5 \%$ trapped $H$ has been observed [24] in the near sub-surface region. (However, it should be noted that evidence [22-24] exists to suggest that much of the incorporated $\mathrm{H}$ is located at grain boundaries in polycrystalline diamond.) Since we have not allowed diffusion or outgassing from 
the film, it is not surprising that the $\mathrm{H}$ atom concentrations in Fig. 3 are slightly higher than is generally observed. Nonetheless, the agreement between the magnitudes of the $\mathrm{H}$ atom concentrations in Fig. 3 and those observed experimentally is encouraging.

Point defects are trapped into the film when non-diamond sites are covered by growing diamond material. Once a site is completely covered by solid material, it can no longer react. In order to trap a defective site (i.e., a vacancy or $\mathrm{H}$ atom), $\mathrm{C}$ must grow around and over the site while leaving the defect site itself undisturbed. Larger molecules are inherently better at covering defect sites than smaller ones, and so the density of vacancies and $\mathrm{H}$ atoms should increase as $\mathrm{C}_{2} \mathrm{H}_{2}$ becomes more important (relative to $\mathrm{CH}_{3}$ ) to growth. According to Table I, the enthalpy change upon $\mathrm{CH}_{3}$ adsorption (Reaction 4) is larger than that upon $\mathrm{C}_{2} \mathrm{H}_{2}$ adsorption (Reaction 5), and so the activation barrier for $\mathrm{CH}_{3}$ desorption (reverse of Reaction 4) is larger than that for $\mathrm{C}_{2} \mathrm{H}_{2}$ desorption (reverse of Reaction 5). Thus $\mathrm{CH}_{3}$ desorption accelerates with temperature faster than does $\mathrm{C}_{2} \mathrm{H}_{2}$ desorption, and deposition from $\mathrm{C}_{2} \mathrm{H}_{2}$ becomes increasingly important relative to $\mathrm{CH}_{3}$ as the temperature is raised. This is reflected in Fig. 4 a which shows the percentage of diamond material deposited from $\mathrm{C}_{2} \mathrm{H}_{2}$ on both the (100) and (111) surfaces as a function of the substrate temperature. (The contribution that $\mathrm{C}_{2} \mathrm{H}_{2}$ makes to growth in these simulations is somewhat higher than expected from experimental evidence [25], perhaps because of the relatively high adsorption and low desorption rates for $\mathrm{C}_{2} \mathrm{H}_{2}$ taken from the calculations of Skokov et al. [13]) As the substrate temperature increases, more of the material is deposited from $\mathrm{C}_{2} \mathrm{H}_{2}$. This leads to an increase in the concentration of incorporated $\mathrm{H}$ atoms with temperature in Fig. 3a, and the trends in $\mathrm{H}$ atom concentration in Fig. $3 \mathrm{a}$ closely follow the trends in growth from $\mathrm{C}_{2} \mathrm{H}_{2}$ in Fig. $4 \mathrm{a}$.

When the concentration of inlet $\mathrm{CH}_{4}$ is varied, the correlation between the concentration of $\mathrm{H}$ atoms and the amount of material deposited from $\mathrm{C}_{2} \mathrm{H}_{2}$ is less obvious. The $\mathrm{H}$ atom defect concentrations in Fig. $3 \mathrm{~b}$ increase with increasing inlet $\mathrm{CH}_{4}$, whereas the contribution to deposition from $\mathrm{C}_{2} \mathrm{H}_{2}$ initially decreases with increasing inlet $\mathrm{CH}_{4}$ concentration under low $\mathrm{CH}_{4}$ flux, and then increases as the concentration of $\mathrm{CH}_{4}$ increases above $3 \%$ (see Fig. $4 \mathrm{~b}$ ). However, increasing the concentration of inlet $\mathrm{CH}_{4}$ creates significant fractions of $\mathrm{sp}^{2}$ bonds on the surface, introducing 
an additional complicating factor to the defect trapping process.

\section{$\mathrm{sp}^{2}$ Defects}

The concentration of $\mathrm{sp}^{2}$ defects at $0.4 \%$ inlet $\mathrm{CH}_{4}$ is about $0.1 \%$ at all of the temperatures examined (see Fig. 3a). $\mathrm{sp}^{2}$ defects are bonds rather than atomic sites and can, therefore, be covered without having to be "encased" like a site defect (i.e., vacancy or $\mathrm{H}$ atom - see above). Therefore the concentration of $\mathrm{sp}^{2}$ defects is not significantly affected by the relative contribution of $\mathrm{C}_{2} \mathrm{H}_{2}$ to growth, and the $\mathrm{sp}^{2}$ defect concentration does not vary substantially with temperature. The concentration of $\mathrm{sp}^{2}$ bonds in Fig. $3 \mathrm{~b}$ increases from about $0.1 \%$ to $1.5 \%$ as the concentration of $\mathrm{CH}_{4}$ in the feed is varied from $0.4 \%$ to $7 \%$. This is because $\mathrm{H}$ is required to convert $\mathrm{sp}^{2}$ bonds on the surface to $\mathrm{sp}^{3}$ bonds (see Reaction 23 in Table I). Thus the density of $\mathrm{sp}^{2}$ bonds on the surface should increase as the rate of Reaction 23 increases. Reaction 23 requires $\mathrm{H}$ to proceed, and so its rate should increase as the concentration of $\mathrm{H}$ increases. Therefore, the decrease in the $\mathrm{H}$ concentration at the surface with increasing $\mathrm{CH}_{4}$ in the feed (see Fig. 1) hinders the conversion of $\mathrm{sp}^{2}$ defects to $\mathrm{sp}^{3}$ diamond at the surface, leaving more $\mathrm{sp}^{2}$ material that can be overgrown by deposition. These predictions are in accord with experiments [26] that show that the $\mathrm{sp}^{2}$ content decreases as the ratio of $\mathrm{H}$ to $\mathrm{CH}_{3}$ in the gas near the surface increases.

\section{Growth Optimization}

Many applications of thin diamond films require high-quality, defect-free material. For example, the performance of diamond-based electronic and optical components depends strongly on the quality of the material. In addition, minimizing production costs and maximizing yield demand high film growth rates. Therefore, the efficient production of diamond films for many applications requires a compromise between maximizing growth rate and minimizing defect density. If the ratio of growth rate to defect concentration is used as a measure of growth 
"efficiency," then a maximum in this indicator would correspond to "ideal" growth conditions. This ratio is shown as a function of temperature in Fig. $5 \mathrm{a}$ using the $\mathrm{H}$ atom defect concentrations and in Fig. 5b using the $\mathrm{sp}^{2}$ defect concentrations; and as a function of inlet $\mathrm{CH}_{4}$ in Fig. $5 \mathrm{c}$ using the $\mathrm{H}$ atom defect concentrations and in Fig. $5 \mathrm{~d}$ as a function of inlet $\mathrm{CH}_{4}$ using the $\mathrm{sp}^{2}$ defect concentrations. (The vacancy concentrations are low, as is typically observed $[1,3]$, and were not considered for the growth efficiency calculations.) The growth efficiencies versus temperature, calculated based on $\mathrm{H}$ atom defects, have maxima around $800-900{ }^{\circ} \mathrm{C}$ in Fig. 5a [10] because the incorporated $\mathrm{H}$ concentrations in Fig. $3 \mathrm{a}$ begin to increase in that temperature range. As mentioned above, the $\mathrm{sp}^{2}$ bond fractions in Fig. 3a do not vary substantially with temperature, and thus the shapes of the curves in Fig. $5 b$ are governed by the growth rate curves in Fig. $2 a$. Therefore, the maximum growth efficiency based on the $\mathrm{sp}^{2}$ defect concentrations occurs around $900-950{ }^{\circ} \mathrm{C}$. These findings are in accord with well-established experimental observations which show that this temperature range produces the best-quality hot-filament CVD diamond $[27,28]$ at relatively high rates, and, hence, it is this temperature range which is widely used for diamond CVD $[3,5,28]$.

The film growth rate in Fig. $2 \mathrm{~b}$, and the $\mathrm{H}$ atom and $\mathrm{sp}^{2}$ bond concentrations in Fig. $3 \mathrm{~b}$, all increase with $\mathrm{CH}_{4}$ concentration. The maximum $\mathrm{sp}^{2}$-based growth efficiency in Fig. $5 \mathrm{~d}$ occurs around $1 \% \mathrm{CH}_{4}$, and the optimum $\mathrm{H}$-based efficiency in Fig. $5 \mathrm{c}$ is around $2-3 \% \mathrm{CH}_{4}$ though the $\mathrm{H}$ atom concentrations in Fig. $3 \mathrm{~b}$ are comparatively low. The quality of hot filament CVD diamond is known to deteriorate due to $\mathrm{sp}^{2}$ bond formation above about $1 \%$ inlet $\mathrm{CH}_{4}[28,29]$ and, hence, inlet $\mathrm{CH}_{4}$ concentrations in the $0.3 \%$ to $1.0 \%$ range are commonly employed $[15,28-31]$. The predictions in Fig. 5b support these observations.

Thus the optimum growth temperature range of about $800-900^{\circ} \mathrm{C}$ in Fig. $5 \mathrm{a}$ is controlled primarily by $\mathrm{H}$ incorporation, and the ideal feed gas composition of about $1 \% \mathrm{CH}_{4}$ in Fig. $5 \mathrm{~d}$ is influenced most by $\mathrm{sp}^{2}$ bond formation. As mentioned above, these findings are in accord with common observations $[3,5,27-29]$. The input parameters to these simulations are the surface chemical kinetics estimated from experimental combustion data, atomistic calculations $[6,12,13]$, and the gas-phase composition at the diamond growth surface adopted from experimentally verified 
transport modeling [19]. Thus the agreement between the predictions made here and typical experimental observations is particularly noteworthy because no adjustable input parameters were used in any part of these simulations. This suggests that the model of diamond deposition employed in this study captures most of the important and general features of actual diamond growth dynamics.

\section{Conclusions}

The growth of diamond films and the rate of incorporation of vacancies, $\mathrm{H}$ atoms, and $\mathrm{sp}^{2}$ defects were simulated for several substrate temperatures and feed gas compositions. An efficient atomic-scale on-lattice kinetic Monte Carlo method was used to capture a simple yet physically meaningful representation of the atomic processes involved in defect trapping. Growth on $(100)(2 \times 1)$ - and (111)-oriented diamond surfaces was simulated for substrate temperatures from $600{ }^{\circ} \mathrm{C}$ to $1200^{\circ} \mathrm{C}$ with $0.4 \%$ inlet $\mathrm{CH}_{4}$, and for $0.4 \%$ to $7 \%$ inlet $\mathrm{CH}_{4}$ concentrations with a substrate temperature of $800^{\circ} \mathrm{C}$. The simulations predict that $\mathrm{H}$ atom defect concentrations increase with substrate temperature as the relative contribution of $\mathrm{C}_{2} \mathrm{H}_{2}$ to deposition increases, simply because the larger $\mathrm{C}_{2} \mathrm{H}_{2}$ molecule can cover defect sites more easily than can $\mathrm{CH}_{3}$. The concentrations of incorporated $\mathrm{sp}^{2}$ bonds increase with the $\mathrm{CH}_{4}$ content in the feed gas because the concentration of $\mathrm{H}$, which is required to convert $\mathrm{sp}^{2}$ bonds to $\mathrm{sp}^{3}$ bonds at the surface, decreases with increasing inlet $\mathrm{CH}_{4}$. Vacancy concentrations are low under all simulated conditions. The ratio of growth rate to $\mathrm{H}$ atom concentration is highest around $800-900{ }^{\circ} \mathrm{C}$, and the growth rate to $\mathrm{sp}^{2}$ ratio is maximum around $1 \% \mathrm{CH}_{4}$, suggesting that these conditions are ideal for diamond growth under the simulated conditions, as is often found experimentally.

\section{Acknowledgments}

The authors wish to thank D.S. Dandy, S.J. Harris, I.I. Oleinik, D.G. Pettifor, and A.P. Sutton 
for enlightening discussions, and D.S. Dandy for providing the gas composition data used in this work. The authors gratefully acknowledge the support of the US Defense Advanced Research Projects Agency and the US Naval Research Laboratory under contract number N00014-96-1G000. This work was performed in part at Sandia National Laboratories under DOE contract number DE-AC04-94AL85000.

\section{References}

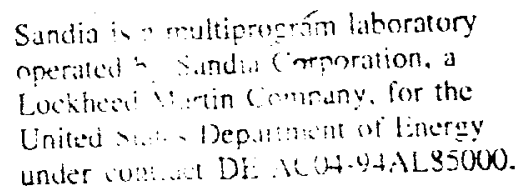

[1] W. Zhu, in Diamond: Electronic Properties and Applications, edited by L. S. Pan, and D. R. Kania (Kluwer, Norwell, MA, 1995) pp. 175-239.

[2] N.C. Burton, J.E. Butler, A.R. Lang, and J.W. Steeds, Proc. R. Soc. Lond. A 449, 555-66 (1995).

[3] D.G. Goodwin and J.E. Butler, in Handbook of Industrial Diamonds and Diamond Films, edited by M. A. Prelas, G. Popovici, and L. K. Bigelow (Dekker, New York, 1997) pp. $527-82$.

[4] J.C. Angus, A. Argoitia, R. Gat, Z. Li, M. Sunkara, L. Wang, and Y. Wang, Phil. Trans. R. Soc. Lond. A 342, 195-208 (1993).

[5] R.C. DeVries, Ann. Rev. Mater. Sci. 17, 161-87 (1987).

[6] M.E. Coltrin and D.S. Dandy, J. Appl. Phys. 74, 5803-20 (1993).

[7] M. Frenklach and H. Wang, Phys. Rev. B 43, 1520-45 (1991).

[8] E.J. Dawnkaski, D. Srivastava, and B.J. Garrison, J. Chem. Phys. 104, 5997-6008 (1996).

[9] M.M. Clark, L.M. Raff, and H.L. Scott, Comp. in Phys. 10, 584-90 (1996).

[10] C. Battaile, D.J. Srolovitz, and J.E. Butler, in Thin Films: Surface and Morphology, edited by R. Cammarata, E. Chason, T. Einstein, and E. Williams, 441 (MRS, Pittsburgh, 1997) pp. 509-14.

[11] D.N. Belton and S.J. Harris, J. Chem. Phys. 96, $2371-7$ (1992).

[12] S.J. Harris and D.G. Goodwin, J. Phys. Chem. 97, 23-8 (1993). 
[13] S. Skokov, B. Weiner, and M. Frenklach, J. Phys. Chem. 99, 5616-25 (1995).

[14] S.J. Harris and A.M. Weiner, Appl. Phys. Lett. 53, 1605-7 (1988).

[15] W.L. Hsu, Appl. Phys. Lett. 59, 1427-9 (1991).

[16] F.G. Celii and J.E. Butler, J. Appl. Phys. 71, 2877-83 (1992).

[17] J. Warnatz, Combustion Chemistry, W. C. Gardiner. 1984, Springer-Verlag: Berlin.

[18] B.J. Garrison, E.J. Dawnkaski, D. Srivastava, and D.W. Brenner, Science 25 5, 835-8 (1992).

[19] D.S. Dandy and M.E. Coltrin, J. Appl. Phys. 76, 3102-13 (1994).

[20] C.C. Battaile, D.J. Srolovitz, and J.E. Butler, J. Appl. Phys. 82, 6293-300 (1997).

[21] A.B. Bortz, M.H. Kalos, and J.L. Lebowitz, J. Comp. Phys. 17, 10-8 (1975).

[22] K.M. McNamara, B.E. Williams, K.K. Gleason, and B.E. Scruggs, J. Appl. Phys. 76 , 2466-72 (1994)

[23] D.C. Ingram, J.C. Keay, C. Tang, M.L. Lake, and J.-M. Ting, Diam. Rel. Mater. 2, 1414-9 (1993).

[24] H. Jia, J. Shinar, D.P. Lang, and M. Pruski, Phys. Rev. B 48, 17595-8 (1993).

[25] C.J. Chu, M.P. D'Evelyn, R.H. Hauge, and J.L. Margrave, J. Appl. Phys. 7 0, 1695-1705 (1991).

[26] S.J. Harris, A.M. Weiner, S. Prawer, and K. Nugent, J. Appl. Phys. 80, 2187-94 (1996).

[27] J.E. Butler and R.L. Woodin, Phil. Trans. R. Soc. Lond. A 342, 209-24 (1993).

[28] K.E. Spear, J. Amer. Ceram. Soc. 72, 171-91 (1989).

[29] E. Kondoh, T. Ohta, T. Mitomo, and K. Ohtsuka, J. Appl. Phys. 73, 3041-6 (1993).

[30] R.E. Rawles, W.G. Morris, and M.P. D'Evelyn, in Diamond for Electronic Applications, edited by D. L. Dreifus, A. Collins, T. Humphreys, K. Das, and P. E. Pehrsson, 416 (MRS, Pittsburgh, 1996) pp. 13-8.

[31] C.J. Chu, R.H. Hauge, J.L. Margrave, and M.P. D'Evelyn, Appl. Phys. Lett. 61, 1393-5 (1992). 


\section{Figure Captions}

Figure 1. Gas composition at the diamond growth surface. The filled symbols are data from modeling [19] and the open symbols are from experimental measurements [15].

Figure 2. Growth rates on the (100)(2x1) and (111) surfaces of diamond as functions of a) substrate temperature with $0.4 \% \mathrm{CH}_{4}$ in the feed gas, and b) $\mathrm{CH}_{4}$ content in the feed with a $800{ }^{\circ} \mathrm{C}$ substrate.

Figure 3. Concentrations of incorporated vacancies, $\mathrm{H}$, and $\mathrm{sp}^{2}$ bond defects in (100)- and (111)oriented diamond films as functions of a) substrate temperature with $0.4 \% \mathrm{CH}_{4}$ in the feed gas, and b) $\mathrm{CH}_{4}$ content in the feed with a $800^{\circ} \mathrm{C}$ substrate.

Figure 4. The percentage of diamond material grown from $\mathrm{C}_{2} \mathrm{H}_{2}$ deposition on the (100)(2x1) and (111) surfaces as a function of a) substrate temperature with $0.4 \% \mathrm{CH}_{4}$ in the feed gas, and b) $\mathrm{CH}_{4}$ content in the feed with a $800{ }^{\circ} \mathrm{C}$ substrate.

Figure 5. The normalized ratio of growth rate to a) incorporated $\mathrm{H}$ concentration and $\mathrm{b}$ ) $\mathrm{sp}^{2}$ bond fraction as functions of substrate temperature with $0.4 \% \mathrm{CH}_{4}$ in the feed gas; and c) incorporated $\mathrm{H}$ and d) $\mathrm{sp}^{2}$ bond fraction as functions of $\mathrm{CH}_{4}$ content in the feed with $\mathrm{a} 800^{\circ} \mathrm{C}$ substrate. 
Table I. Diamond growth reactions, kinetics, and thermochemistry [6,11-13].

\begin{tabular}{|c|c|c|c|c|c|}
\hline Reaction & $A$ & $n$ & $E$ & $\Delta H$ & $\Delta S$ \\
\hline $\mathrm{C}_{\mathrm{d}} \mathrm{H}+\mathrm{H} \leftrightarrow \mathrm{C}_{\mathrm{d}}+\mathrm{H}_{2}$ & $1.3 \times 10^{14}$ & 0 & 7.3 & -9.9 & 5.3 \\
\hline $\mathrm{C}_{\mathrm{d}}+\mathrm{H} \leftrightarrow \mathrm{C}_{\mathrm{d}} \mathrm{H}$ & $1.0 \times 10^{13}$ & 0 & 0.0 & -96.9 & -32.8 \\
\hline $\mathrm{C}_{\mathrm{d}} \mathrm{CH}_{2}+\mathrm{H} \leftrightarrow \mathrm{C}_{\mathrm{d}}+\mathrm{CH}_{3}$ & $3.0 \times 10^{13}$ & 0 & 0.0 & -24.6 & 7.9 \\
\hline $\mathrm{C}_{\mathrm{d}}+\mathrm{CH}_{3} \leftrightarrow \mathrm{C}_{\mathrm{d}} \mathrm{CH}_{3}$ & $5.0 \times 10^{12}$ & 0 & 0.0 & -70.9 & -42.0 \\
\hline $\mathrm{C}_{\mathrm{d}}+\mathrm{C}_{2} \mathrm{H}_{2} \leftrightarrow \mathrm{C}_{\mathrm{d}} \mathrm{C}_{2} \mathrm{H}_{2}$ & $4.5 \times 10^{11}$ & 0 & 6.9 & -28.5 & -1.9 \\
\hline $\mathrm{C}_{\mathrm{d}} \mathrm{CH}_{\mathrm{y}}+\mathrm{H} \leftrightarrow \mathrm{C}_{\mathrm{d}} \mathrm{CH}_{\mathrm{y}-1}+\mathrm{H}_{2}$ & $2.8 \times 10^{7}$ & 2 & 7.7 & -11.3 & 6.6 \\
\hline $\mathrm{C}_{\mathrm{d}} \mathrm{CH}_{\mathrm{y}}+\mathrm{H} \leftrightarrow \mathrm{C}_{\mathrm{d}} \mathrm{CH}_{\mathrm{y}+1}$ & $1.0 \times 10^{13}$ & 0 & 0.0 & -83.0 & -34.1 \\
\hline $\mathrm{C}_{\mathrm{d}} \mathrm{C}_{2} \mathrm{H}_{\mathrm{y}}+\mathrm{H} \leftrightarrow \mathrm{C}_{\mathrm{d}} \mathrm{C}_{2} \mathrm{H}_{\mathrm{y}-1}+\mathrm{H}_{2}$ & $9.0 \times 10^{6}$ & 2 & 5.0 & -8.9 & 8.7 \\
\hline $\mathrm{C}_{\mathrm{d}} \mathrm{C}_{2} \mathrm{H}_{\mathrm{y}}+\mathrm{H} \leftrightarrow \mathrm{C}_{\mathrm{d}} \mathrm{C}_{2} \mathrm{H}_{\mathrm{y}+1}$ & $2.0 \times 10^{13}$ & 0 & 0.0 & -47.7 & -36.2 \\
\hline $\mathrm{C}_{\mathrm{d}} \mathrm{C}_{2} \mathrm{H}_{\mathrm{y}}+\mathrm{H} \leftrightarrow \mathrm{C}_{\mathrm{d}} \mathrm{CH}_{\mathrm{y}-2}+\mathrm{CH}_{3}$ & $3.0 \times 10^{13}$ & 0 & 0.0 & -24.6 & 7.9 \\
\hline 11. $\mathrm{C}_{\mathrm{d}} \mathrm{CH}_{\mathrm{y}}+\mathrm{CH}_{3} \leftrightarrow \mathrm{C}_{\mathrm{d}} \mathrm{C}_{2} \mathrm{H}_{\mathrm{y}+3}$ & $5.0 \times 10^{12}$ & 0 & 0.0 & -70.9 & -42.0 \\
\hline 12. $\mathrm{C}_{\mathrm{d}}+*+\mathrm{C}_{\mathrm{d}} \mathrm{C}_{\mathrm{x}} \mathrm{H}_{\mathrm{y}} \rightarrow \mathrm{C}_{\mathrm{d}}+\mathrm{C}_{\mathrm{d}} \mathrm{C}_{\mathrm{x}-1} \mathrm{H}_{\mathrm{y}}+\mathrm{C}_{\mathrm{d}}$ & $2.0 \times 10^{13}$ & 0 & 8.8 & ---- & ---- \\
\hline $\mathrm{H}+\mathrm{H} \leftrightarrow \mathrm{C}_{\mathrm{d}} \cdot \mathrm{C}_{\mathrm{d}}+\mathrm{H}_{2}$ & $2.5 \times 10^{14}$ & 0 & 7.3 & -6.2 & 6.7 \\
\hline${ }_{d}+\mathrm{H} \leftrightarrow \mathrm{C}_{d} \cdot \mathrm{C}_{d} \mathrm{H}$ & $1.0 \times 10^{13}$ & 0 & 0.0 & -100.6 & -34.2 \\
\hline 15. $\mathrm{C}_{\mathrm{d}} \bullet \mathrm{C}_{\mathrm{d}} \mathrm{CH}_{2}+\mathrm{H} \leftrightarrow \mathrm{C}_{\mathrm{d}} \cdot \mathrm{C}_{\mathrm{d}}+\mathrm{CH}_{3}$ & $3.0 \times 10^{13}$ & 0 & 0.0 & -17.8 & 8.0 \\
\hline 16. $\mathrm{C}_{\mathrm{d}} \cdot \mathrm{C}_{\mathrm{d}}+\mathrm{CH}_{3} \leftrightarrow \mathrm{C}_{\mathrm{d}} \cdot \mathrm{C}_{\mathrm{d}} \mathrm{CH}_{3}$ & $5.0 \times 10^{12}$ & 0 & 0.0 & -81.0 & -42.2 \\
\hline 17. $\quad \mathrm{C}_{\mathrm{d}} \bullet \mathrm{C}_{\mathrm{d}} \leftrightarrow \mathrm{C}_{\mathrm{d}}+*+\mathrm{C}_{\mathrm{d}}$ & $1.0 \times 10^{13}$ & 0 & 0.0 & 4.9 & 0.4 \\
\hline $\mathrm{C}_{\mathrm{g}} \mathrm{H}+\mathrm{H} \leftrightarrow \mathrm{C}_{\mathrm{g}}+\mathrm{H}_{2}$ & $1.3 \times 10^{12}$ & 0 & 7.3 & -2.7 & 4.4 \\
\hline $\mathrm{C}_{\mathrm{g}}+$ & $1.0 \times 10^{12}$ & 0 & 0.0 & -104.0 & -32.0 \\
\hline $\mathrm{C}_{\mathrm{g}} \mathrm{CH}_{2}^{\mathrm{g}}+\mathrm{H} \leftrightarrow \mathrm{C}_{\mathrm{g}}^{\mathrm{g}}+\mathrm{CH}_{3}$ & $3.0 \times 10^{12}$ & 0 & 0.0 & -24.6 & 7.9 \\
\hline $\mathrm{C}_{\mathrm{g}}+\mathrm{CH}_{3} \leftrightarrow \mathrm{C}_{\mathrm{g}}^{\mathrm{g}} \mathrm{CH}_{3}$ & $5.0 \times 10^{11}$ & 0 & 0.0 & -90.7 & -44.8 \\
\hline $\mathrm{C}_{\mathrm{g}}+\mathrm{C}_{2} \mathrm{H}_{2} \leftrightarrow \mathrm{C}_{\mathrm{g}}^{\mathrm{g}} \mathrm{C}_{2} \mathrm{H}_{2}$ & $4.5 \times 10^{10}$ & 0 & 6.9 & -28.5 & -1.9 \\
\hline $\mathrm{C}_{\mathrm{g}}+\mathrm{C}_{\mathrm{g}}+\mathrm{H} \leftrightarrow \mathrm{C}_{\mathrm{d}}^{\mathrm{g}}+\mathrm{C}_{\mathrm{d}} \mathrm{H}$ & $5.2 \times 10^{12}$ & 0 & 0.0 & -45.8 & -32.0 \\
\hline
\end{tabular}

$A$ is in moles, $\mathrm{cm}^{3}$, and sec as appropriate; $E$ and $\Delta H$ are in kcal; and $\Delta S$ is in cal/mole $\bullet \mathrm{K}$. 


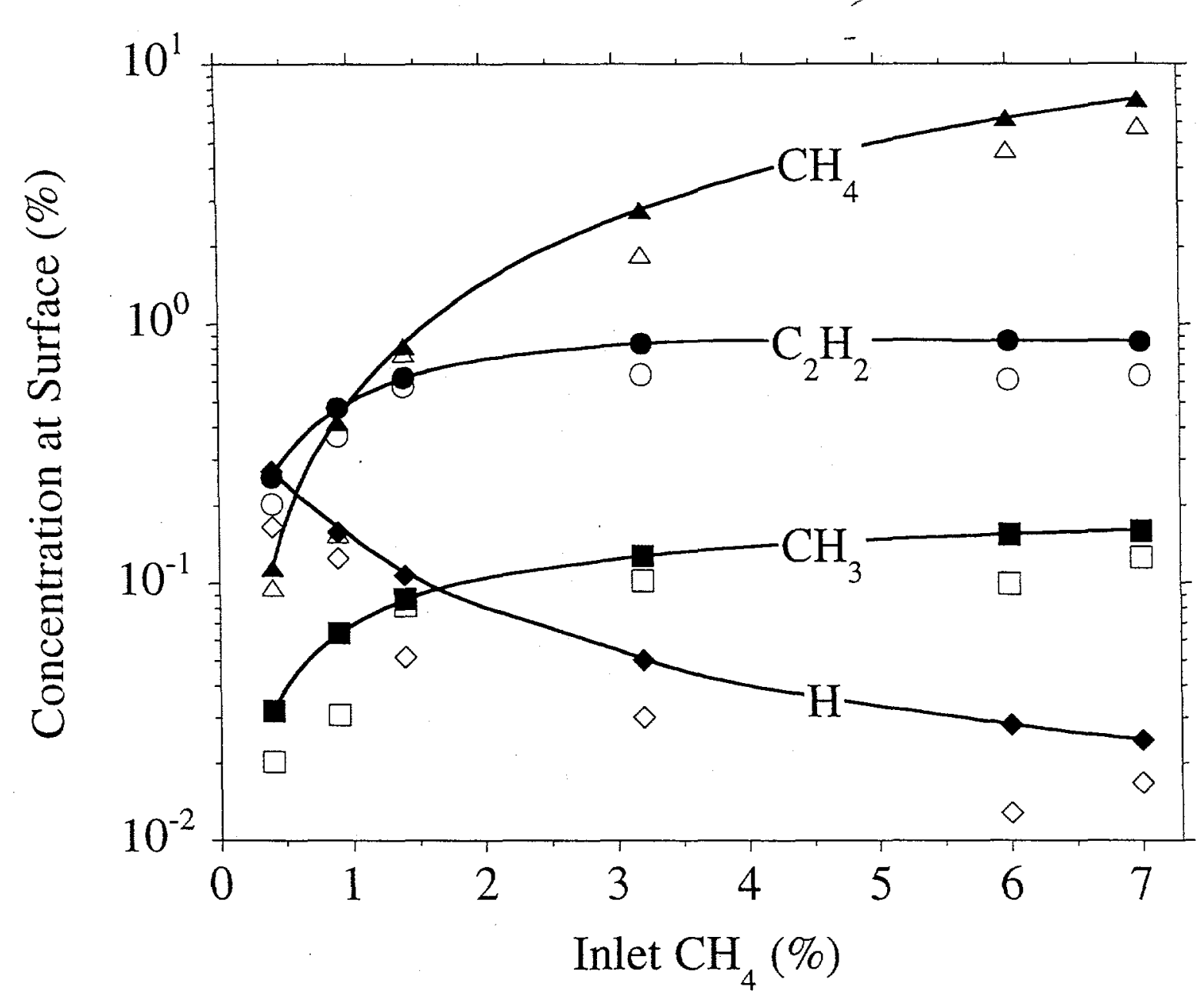

Figure 1 


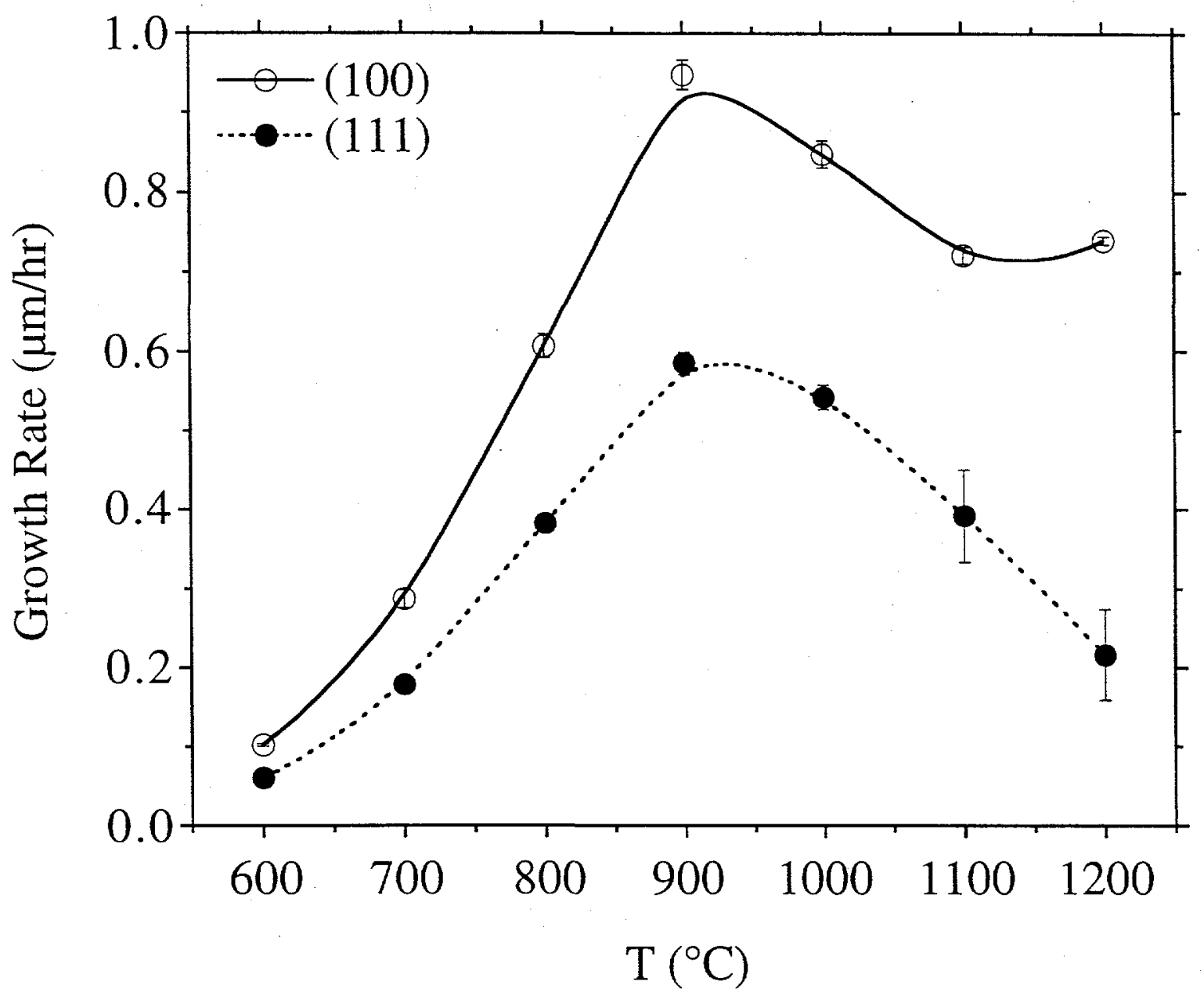

Figure 2a 


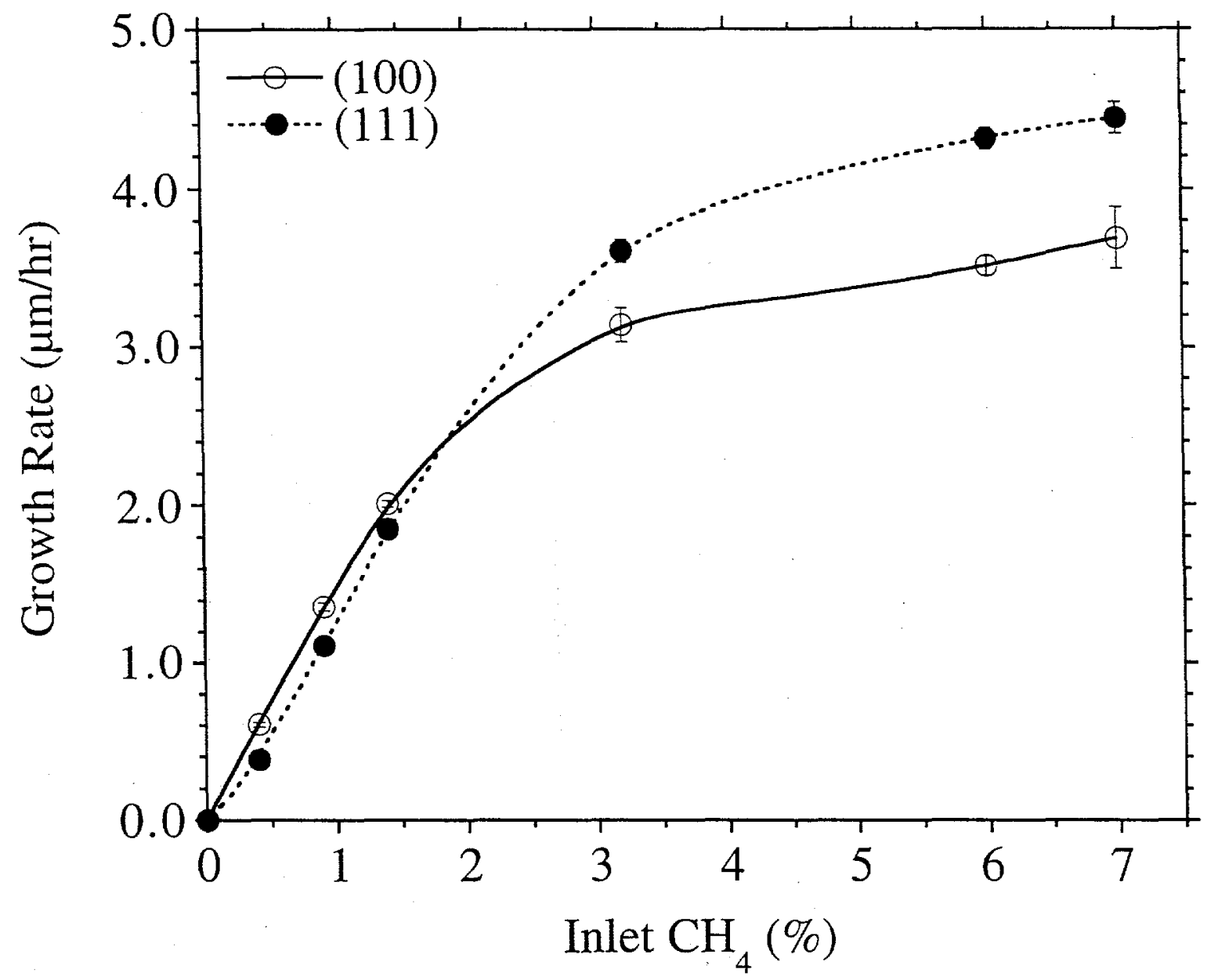

Figure $2 b$ 


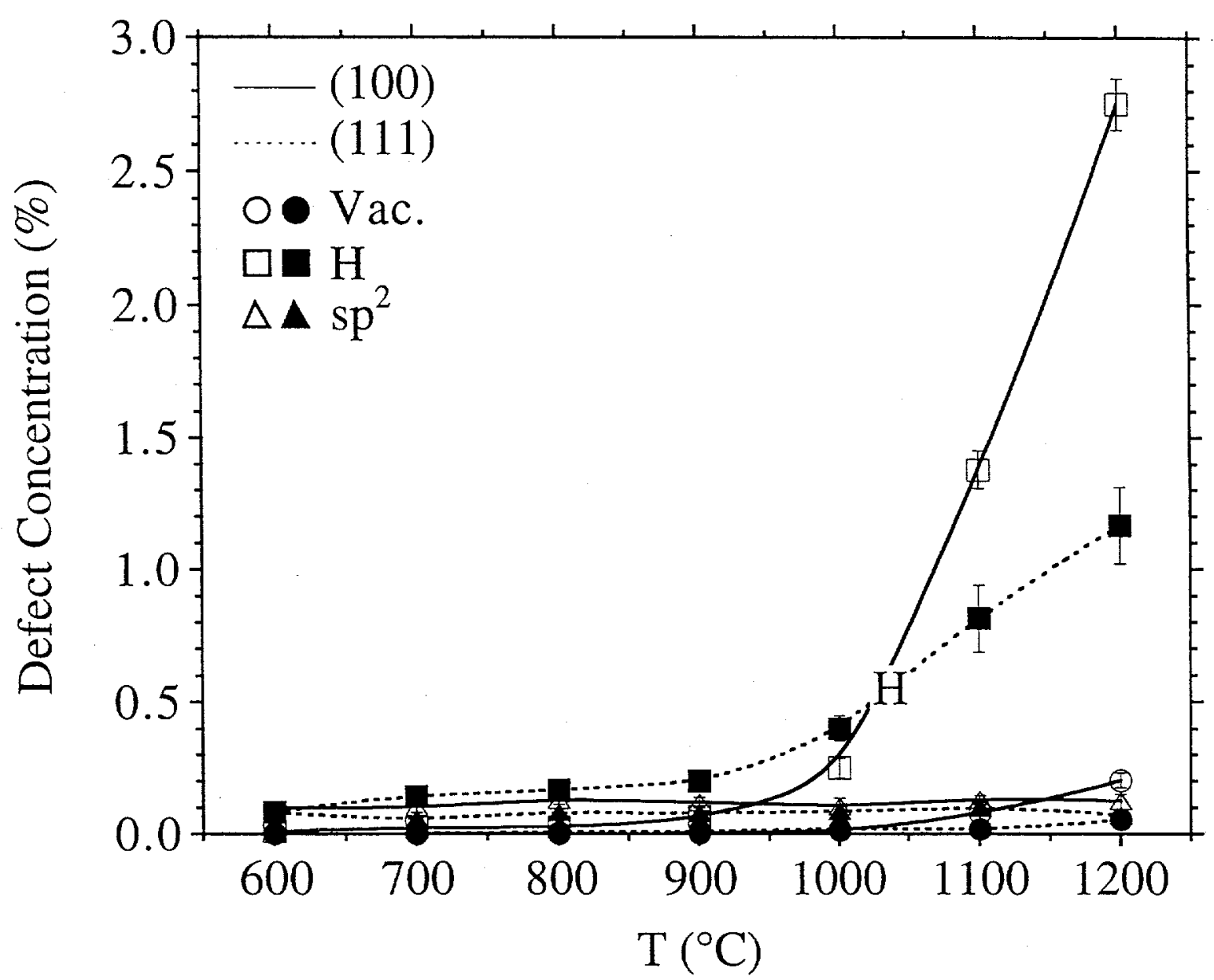

Figure $3 \mathrm{a}$ 


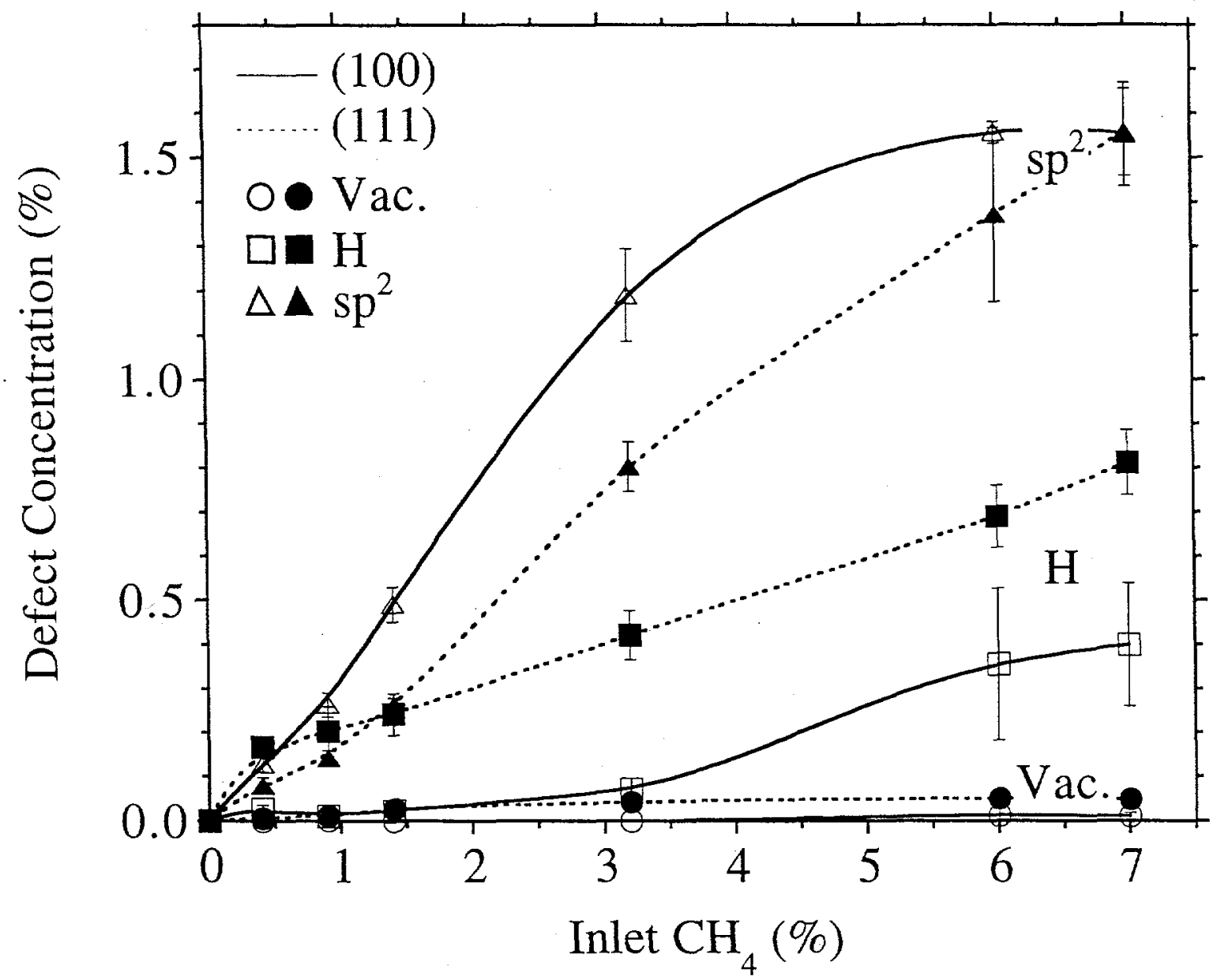

Figure $3 b$ 


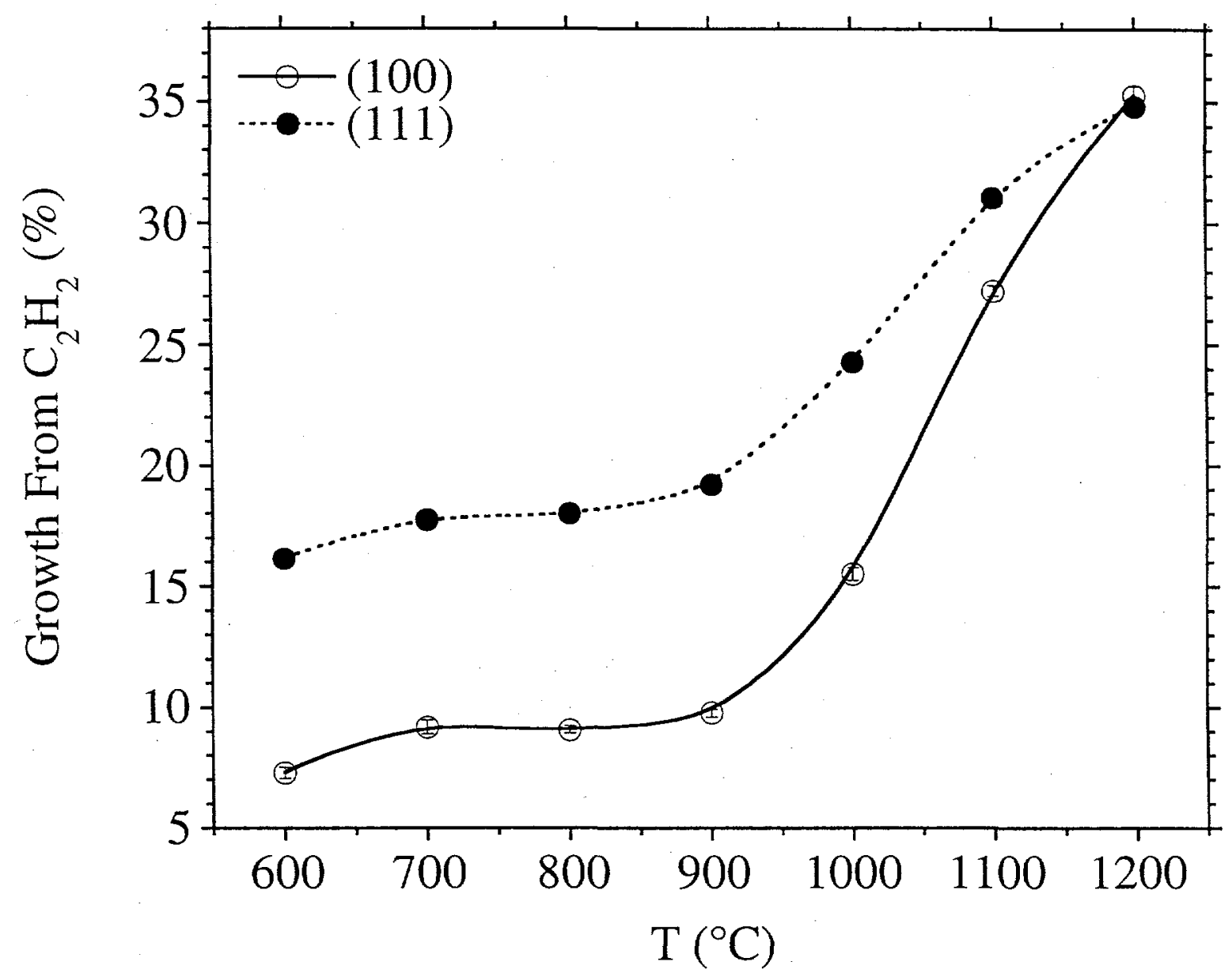

Figure 4a 


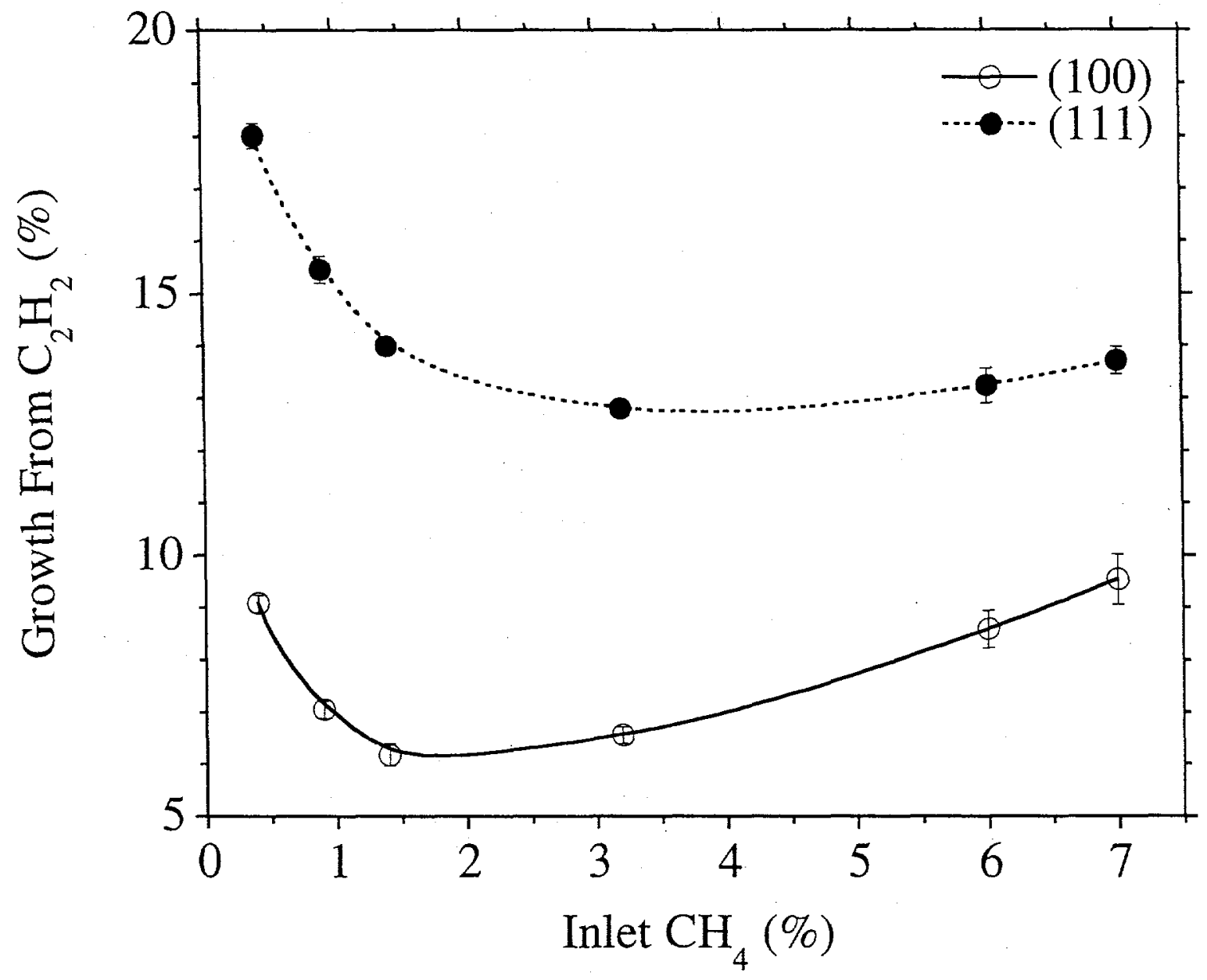

Figure 4b

C.C. Battaile, D.J. Srolovitz, J.E. Butler "Simulations of Defect Incorporation During Diamond CVD" 


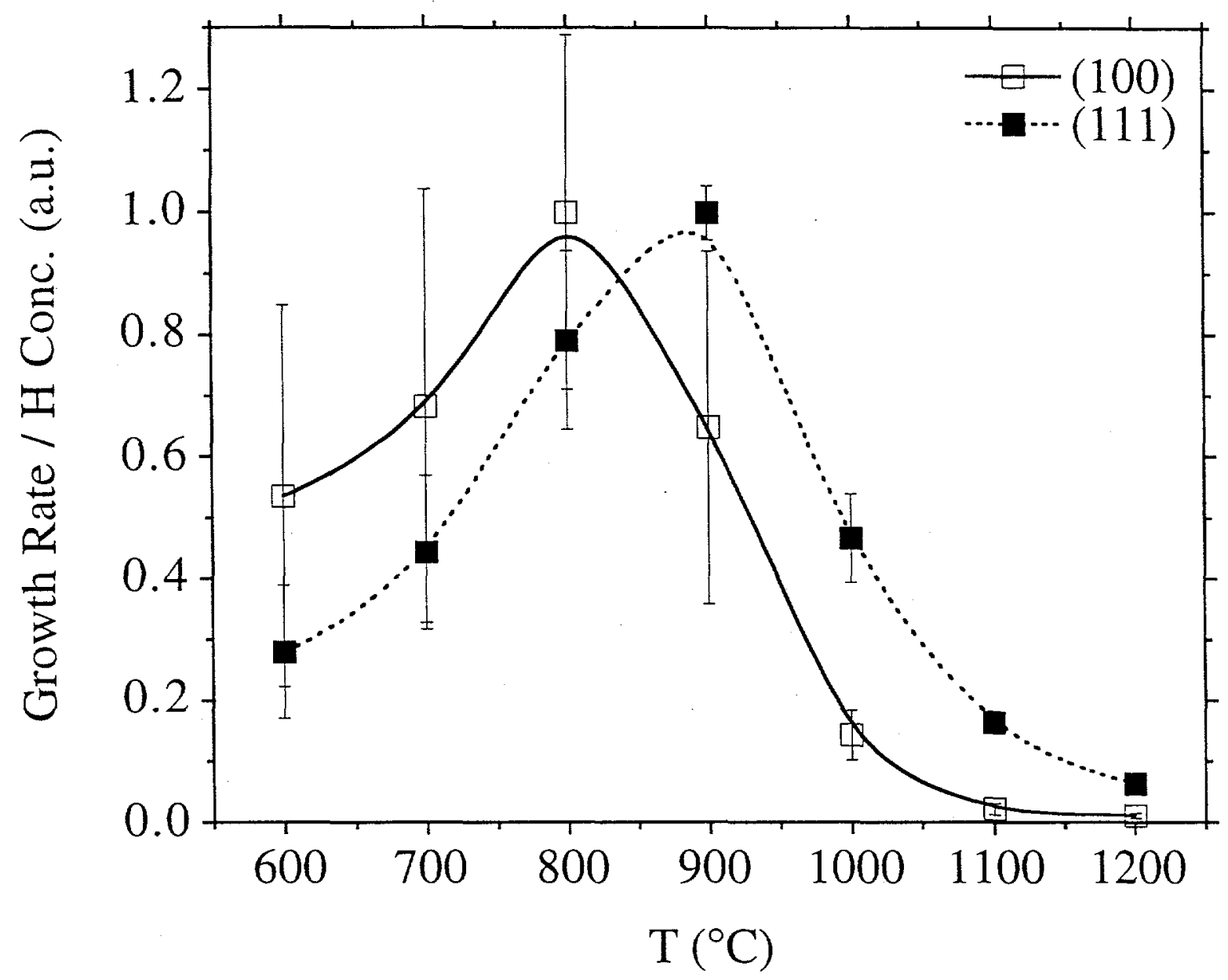

Figure 5a 


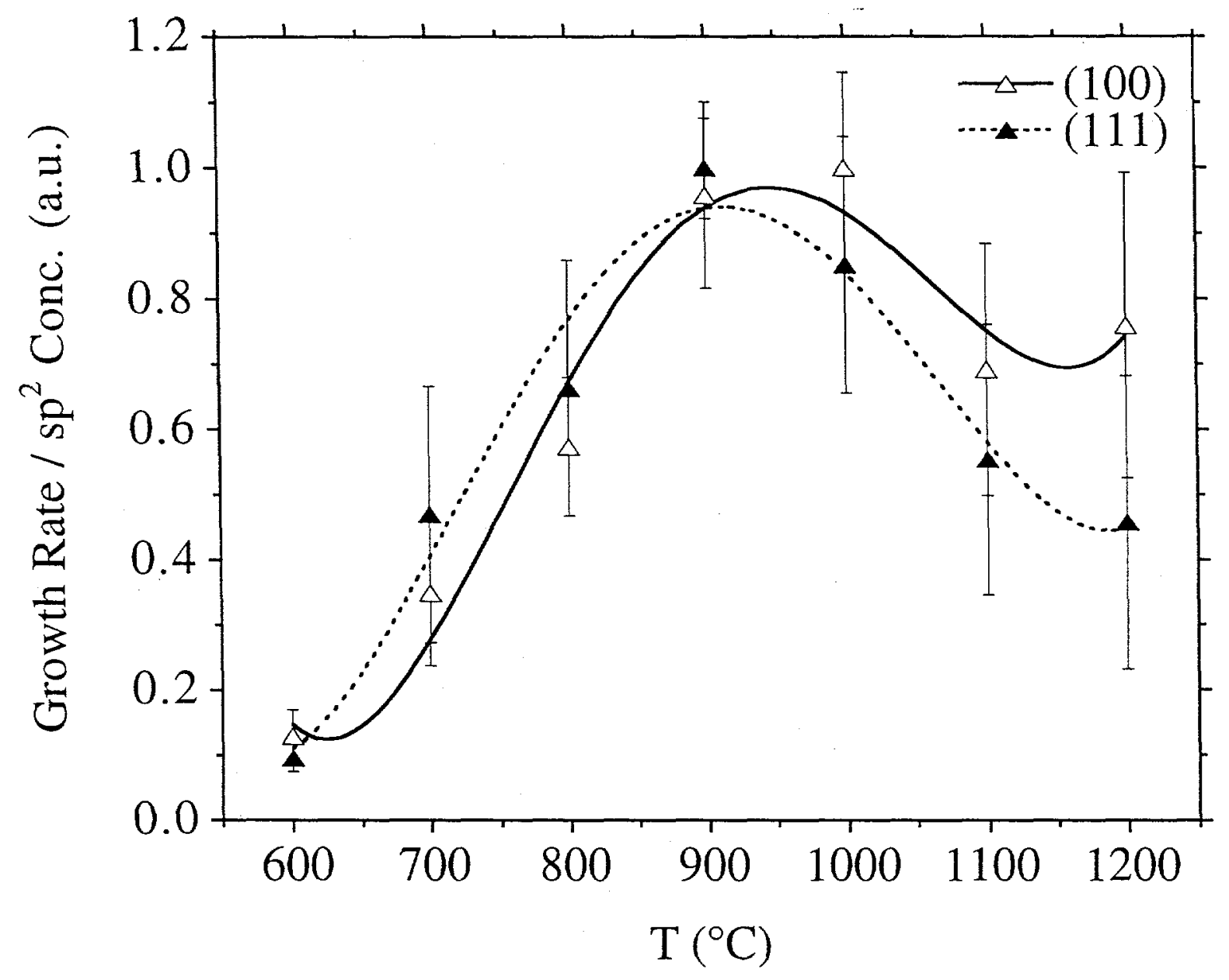

Figure 5b 


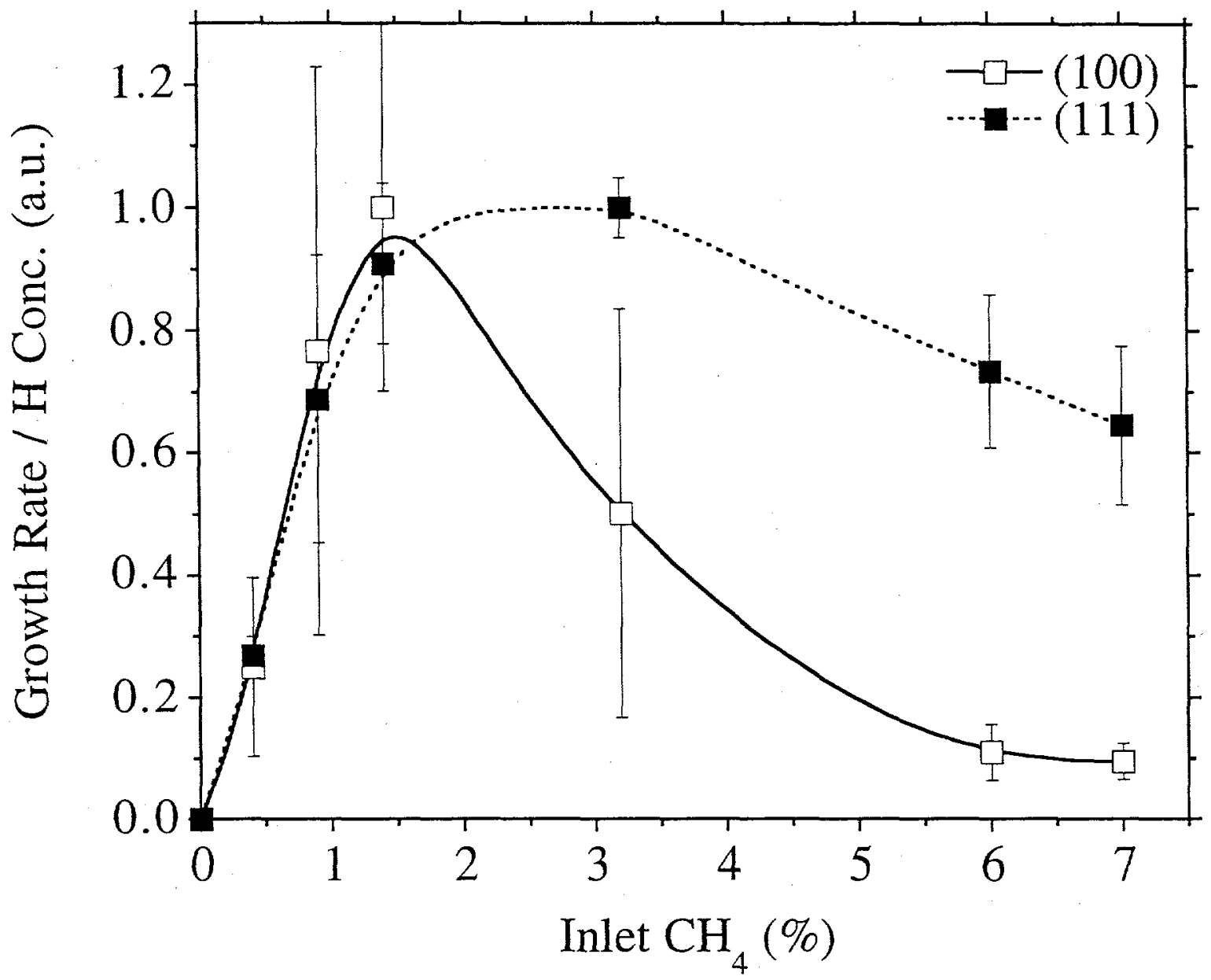

Figure 5c 


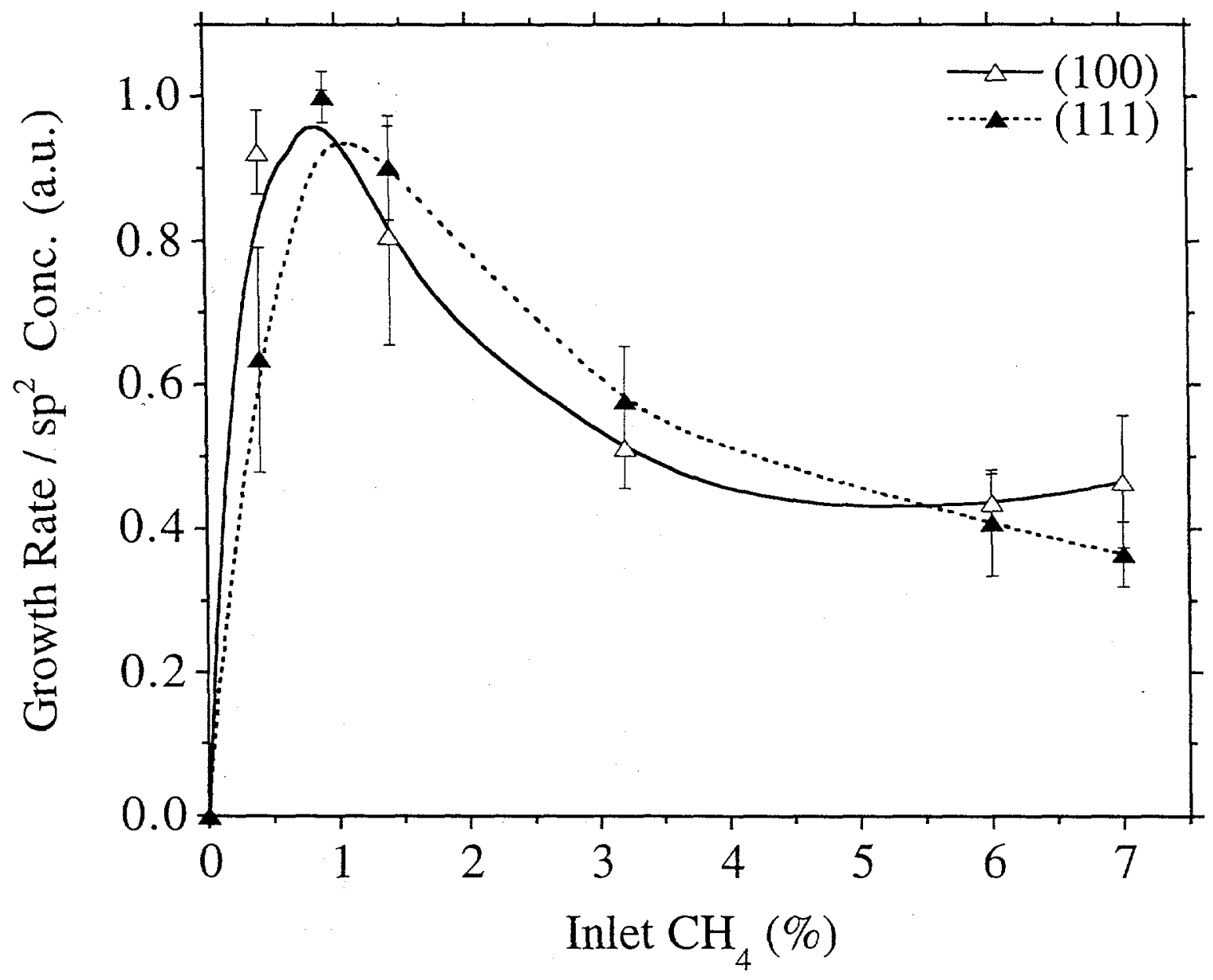

Figure 5d 